\title{
Technical note \\ Measurement and expression of granular filter cleanliness
}

\author{
Johannes Haarhoff and Samantha van Staden* \\ Department of Civil Engineering Science, University of Johannesburg, PO Box 524, Auckland Park 2006, South Africa
}

\begin{abstract}
The problem of dirty filter media at water treatment plants, despite having good backwash systems, is a serious challenge that requires constant monitoring and maintenance. To aid the systematic analysis of filter media and the troubleshooting of problem filters, this paper firstly proposes a standard procedure for quantification of the specific deposit on filter media, including tentative guidelines for the interpretation of the results. Secondly, a standard procedure is proposed for the characterisation of the specific deposit, based on its volatility and its acid solubility. These fractions are helpful to trace the origin of excessively dirty filter media. Thirdly, the utility of the proposed procedures is demonstrated by the results of a South African treatment plant survey. This confirms some earlier observations that there often is a real problem with recalcitrant specific deposits that cannot be readily removed by backwashing, a fraction that correlates with the organic fraction in the specific deposit.
\end{abstract}

Keywords: backwashing, specific deposit, filter media, filter cleanliness

\section{INTRODUCTION}

Filtration theory suggests that a sand filter starts its life with new, perfectly clean media. During each filtration cycle, its media pores become gradually clogged as the particles are trapped, forming specific deposit. When the specific deposit builds up to a point where either the head loss or the filtrate quality reach their acceptable limits, the backwash cycle is initiated. The combined action of air and water quickly returns the media to its original perfectly clean state, and so the cycle continues.

The reality is different. It is common practice to return to a treatment plant a decade or more after its commissioning to find filter sand that is unacceptably dirty, with backwash systems that are clearly incapable of cleaning the media to its initial state of cleanliness. Frequently, it is easy to pinpoint the source of the problem - faulty design, substandard construction practices, gross negligence of operators, well-meant but disastrous attempts to correct earlier problems, etc. These problems have been systematically reviewed in a previous publication (Lombard and Haarhoff, 1995). However, in a significant number of cases, the reasons for the media deterioration remain elusive. The design, construction and operation seem to be on par with the best international practice, yet the media steadily becomes dirtier and dirtier.

Excessively dirty filters are identified when mudballs are evident in the media bed. The eminent John Baylis of Chicago stated as early as 1935 that 'mud balls and clogged places in rapid sand filters are the cause of more filter bed trouble than any other single thing' (Baylis, 1935a). In the same year, he published a method for measuring the mudball volume in a filter bed, with guidelines for its interpretation (Baylis, 1935b). If the mudball volume is below $0.1 \%$ of the media volume, the

To whom all correspondence should be addressed.

+27 11559 2395; e-mail: samvs@uj.ac.za

Received 20 March 2013; accepted in revised form 23 September 2013. condition of the filter bed could be considered 'excellent'; above $5.0 \%$ the condition would be 'very bad'. It was shown that mudballs start to grow around sand grains with low specific gravity of about 1.2, but as they grow, the material compacts and becomes a real problem when the specific gravity reaches about 1.6 - a point where they cannot readily be washed out. Early mudball formation indicated by small mudballs can thus be most commonly seen after backwashing in the top $150 \mathrm{~mm}$ of a bed. Older, larger mudballs are heavier and sink to positions of low upward velocity in corners and along walls (Hudson, 1981).

A likely argument is that the detection of mudballs already indicates an advanced state of media deterioration. Could one not get an early warning before mudballs can be detected? To do this, a more sensitive procedure is required which will strip and quantify the thin layer of specific deposit from the media grains before mudball formation. Such a method was proposed by Kawamura (Kawamura, 2000). He provided a detailed procedure for sampling a media bed, as well as stripping the specific deposit by vigorous shaking of the media in the presence of water. The turbidity of the water decanted off the media is then used with a 4-point scale for assessing filter cleanliness - clean, slightly dirty, dirty with need for closer evaluation, and problems with mudballs. The procedure was called the 'mud retention analysis' and 'sludge retention analysis'. To encourage more systematic filter assessment and maintenance, a comprehensive guidance manual was published shortly thereafter, which incorporated the Kawamura procedure, labelled as the 'floc retention analysis' (Logsdon et al., 2002).

In South Africa, problems with dirty filter media are commonly experienced, exacerbated by highly eutrophic surface water at high temperatures. These conditions are conducive to the formation of biofilm in the filter media, which had been conclusively shown to inhibit the effective backwashing of sand and carbon filters (Clements, 2002). A systematic investigation into filter media cleanliness was therefore started around 2002 at the University of Johannesburg (up to 2004, the Rand Afrikaans University). This paper provides some pertinent findings of this work regarding: 
- A conceptual framework for systematic analysis of specific deposit

- Standardised methods for the analysis and expression of specific deposit

- Characterisation of the specific deposit and its interpretation

- Setting revised benchmarks for filter media cleanliness

\section{METHODOLOGY}

\section{A conceptual framework for media cleanliness}

The proposed framework recognises 5 different states of media cleanliness:

- BBW (before backwash). The media cleanliness after a typical filter run at the treatment plant, before the media is cleaned by the treatment plant backwash system.

- ABW (after backwash). The media cleanliness after the media had been backwashed by the backwash system at the treatment plant. Where the same filter bed had been subjected to more than one consecutive wash, the state of cleanliness is designated by ABW[1] after the first wash, ABW[2] after the second wash, and so on.

- ACW (after column wash). The media cleanliness after the media had been washed under optimal, standardised conditions in a laboratory column. This backwash rate is selected to attain about $50 \%$ bed expansion and the wash is continued for $5 \mathrm{~min}$.

- APS (after physical stripping). The media cleanliness after it had been subjected to standardised agitation and rinsing in the laboratory. The standardised agitation procedure was the subject of much of our investigations, to be covered in the next section.

- ACS (after chemical stripping). The media cleanliness after it had been immersed in a strong acid. After ACS, the media should be returned to practically the same state as when it was new.

The rationale for choosing the above 5 states of cleanliness becomes apparent when they are used to separate the specific deposit into 4 fractions:

- $[\mathrm{BBW}-\mathrm{ABW}$ quantifies the specific deposit removed by the treatment plant backwash system. If BBW is determined at the end of a filter run when the filter is at its dirtiest, this fraction provides a measure of how much specific deposit is washed out during a typical plant backwash. If multiple consecutive wash cycles are conducted, the amount of specific deposit washed out during consecutive washes are given by [BBW - ABW(1)], [ABW(1) - ABW(2)], etc.

- $\quad[\mathrm{ABW}-\mathrm{ACW}]$ quantifies the additional specific deposit washed out in the laboratory, which cannot be washed out at the treatment plant. If this is a small quantity, it would indicate an efficient treatment plant backwash system that performs almost as well as the laboratory method under optimal conditions. If it is a large quantity, it points to a deficient plant backwash system that needs to be corrected.

- $\quad$ ACW - APS] quantifies the specific deposit which can be removed by physical stripping in the laboratory, which cannot be washed out in the laboratory under optimal conditions. This fraction represents a recalcitrant, sticky part of the specific deposit which will not be removed regardless of how well the plant backwash system works. If this is a large quantity, it points to a problem with the raw water and/or dosing strategy that requires more attentive monitoring and filter bed maintenance.

- $\quad$ APS - ACS] quantifies the specific deposit that cannot be readily removed from the media by physical means, but which requires chemical stripping. If this is a large quantity, it points to an incorrect dosing strategy which encourages chemical precipitation onto the filter media.

\section{Quantifying the specific deposit}

There are 2 experimental options to measure the 4 fractions of the specific deposit identified above:

- The specific deposit removed can be determined from the media by subtracting, for example, the specific deposit of the ABW sample from the specific deposit of the BBW sample - the media method.

- The specific deposit removed can also be determined from the backwash water that is carried away - the washout method. The mass of solids washed out is determined from the backwash rate and the concentration of suspended solids in the backwash water. By dividing the total mass of solids washed out by the total media bed volume, the solids washout can be converted to specific deposit (Appendix 2).

In theory, these two methods should give the same results, but there are practical obstacles in the paths of both. If the media is dirty and the fraction removed is small, the media method faces the imprecision inherent in a small difference between two large numbers. The washout method, in turn, suffers from the inevitable time lag before sampling and the difficulty of taking representative samples from a large flow of backwash water, which is not necessarily homogenous in terms of its suspended solids concentration. Having done both measurements in parallel on many occasions, the authors found a combination of methods to provide the most robust results:

- Measure the [BBW - ABW] and [ABW - ACW] fractions directly from the backwash water coming off the plant and column respectively.

- Measure the specific deposit of the ABW and APS samples directly.

- Measure the [APS - ACS] fraction gravimetrically as the mass difference before and after acid immersion.

\section{Expression of specific deposit}

The specific deposit of filter media is usually expressed in deepbed filtration literature as a dimensionless (mass of specific deposit / mass of media) ratio - a number very small upon quantification. If specific deposit has to be expressed as a mass/ mass ratio, it is more conveniently expressed as $\mathrm{mg} / \mathrm{g}$, as the authors had done in their earlier publications (Van Staden and Haarhoff, 2004a, 2004c). As more case studies were investigated with a variety of different media types, it became obvious that the results could not be directly compared as the densities of silica, anthracite and activated carbon are different. The specific deposit, however, has more to do with the voids amongst the grains than the grains themselves. In the interest of a more universal expression of specific deposit, which is independent of the media grain density, it is suggested that the specific deposit should be expressed as the mass of solids per bulk volume of media, with the units in $\mathrm{kg} / \mathrm{m}^{3}$, which are also easier to imagine. The conversion between mass/mass ratio and mass/ volume ratio, if required, is straightforward, requiring only the media grain density and bed porosity. 
It should be noted that the above recommendation is a significant departure from the Kawamura method which expresses media cleanliness as NTU/100g of media. (The turbidity is measured on the dirty water decanted from the media after vigorous shaking.) Our work showed that, during any one site visit, the ratio between turbidity and suspended solids are reasonably constant, which allows conversion from turbidity to suspended solids if the ratio is known. The ratio, however, is not the same for different raw waters or even for different site visits at the same treatment plant, ranging from as low as 0.337 $\mathrm{NTU}=1 \mathrm{~g} \mathrm{SS} / \ell$ to $1.468 \mathrm{NTU}=1 \mathrm{~g} \mathrm{SS} / \ell(n=762$; during 44 site visits, median $0.709 \mathrm{NTU}=1 \mathrm{~g} \mathrm{SS} / \ell$ ) (Haarhoff et al., 2008).

\section{Stripping the specific deposit from the media}

The specific deposit consists of 'hard' as well as 'soft' deposits. The hard deposits, which are chemically precipitated on the grains, become part and parcel of the media which will not wash off, but will require a strong acid for dissolution. In terms of the framework above, the hard deposits make up the [APS - ACS[ fraction. The other three fractions make up the 'soft' deposits, which determine the filter media cleanliness.

How does one define the transition from 'hard' to 'soft' deposits? This question was thoroughly probed during the early phase of our investigation (Van Staden and Haarhoff, 2004a). The Kawamura method suggested 5 cycles of vigorously shaking $50 \mathrm{~g}$ of media with $100 \mathrm{~m} \ell$ water for $30 \mathrm{~s}$, decanting the supernatant after every cycle until $500 \mathrm{~m} \ell$ of dirty water is collected. Using this as a starting point, 6 different physical stripping methods were compared -3 manual methods and 3 mechanical methods - using $50 \mathrm{~g}$ of sample with $100 \mathrm{~m} \ell$ of water for 5 cycles in all cases. The manual methods were (i) vigorous shaking by hand for $30 \mathrm{~s}$, (ii) hand swirling in an Erlenmeyer flask for $30 \mathrm{~s}$ and (iii) inverting a measuring cylinder 20 times. The mechanical methods agitated the media by (i) orbital shaker table, (ii) by jar tester and (iii) by magnetic stirrer. Replicate tests with different operators conclusively showed that cylinder inversion was the best compromise between reproducibility and simplicity. The shaker table and hand swirling methods were too gentle and consequently removed significantly less deposit. Vigorous shaking was heavily dependent on the operator, with the most aggressive operator removing almost 5 times more deposit than the meekest. Moreover, as the operators tired, they all removed progressively less deposit.

The cylinder inversion method is hence recommended for the physical stripping of the specific deposit and described in detail in Appendix 1.

\section{Sampling the media bed}

It is normally suggested that the filter bed is sampled at different depths, in order to obtain a profile of specific deposit distribution throughout the bed (Kawamura, 2000; AWWA, 1990). Our experience eventually suggested a modified procedure. First, the top $10 \mathrm{~mm}$ of the bed was scraped clean before a core sample was taken from the bed. This is to avoid the inevitable debris lying on or just below the surface. If one or more of these tiny fragments (mostly small flakes of consolidated flocs) ended up in the $50 \mathrm{~g}$ of media used for the stripping of the specific deposit, the results could be skewed. Second, the core sample was taken through the entire media bed. Our results from vertical profiling showed that the specific deposit after backwash varied little throughout, indicating that the [BBW
TABLE 1

Guidelines for the interpretation of [ABW - APS] results

\begin{tabular}{|l|c|c|c|}
\hline \multirow{2}{*}{ State of media } & \multicolumn{2}{|c|}{ Kawamura guideline } & SA guideline \\
\cline { 2 - 4 } & $\begin{array}{c}\text { NTU / 100 g } \\
\text { (wet) }\end{array}$ & $\begin{array}{c}\mathbf{k g} / \mathbf{m}^{\mathbf{3}} \\
\text { (dry media) }^{*}\end{array}$ & $\begin{array}{c}\mathbf{k g} / \mathbf{m}^{3} \\
\text { (dry media) }\end{array}$ \\
\hline Clean & $<30$ & $<0.7$ & $<2$ \\
\hline Clean and ripened & $30-60$ & $0.7-1.4$ & $2-4$ \\
\hline Slightly dirty & $60-120$ & $1.4-2.7$ & $4-7$ \\
\hline Dirty & $120-300$ & $2.7-6.9$ & $7-15$ \\
\hline Mudball problem & $>300$ & $>6.9$ & $>15$ \\
\hline
\end{tabular}

*Assuming 15\% moisture content, silica density $2650 \mathrm{~kg} / \mathrm{m}^{3}$, porosity 0.48 and $0.709 \mathrm{NTU}=1 \mathrm{mgSS} / \mathrm{\ell}$

"Kawamura (2000)

${ }^{+}$Haarhoff and Van Staden (2006)

- ABW] fraction was partly masked by the other soft deposits not washed from the filter bed. Third, the media sample was passed through a small riffle splitter before $50 \mathrm{~m} \ell$ was scooped out with a calibrated plastic spoon. Three scoops were taken from the same media sample and analysed independently to provide 3 replicate results. Fourth, significant variation was found in the moisture content of different samples. (The average moisture content measured on all our media samples was $15 \%$.) An additional sample had therefore to be taken and its moisture content determined to allow the correction of the wet media mass in the three scoops to dry media mass.

\section{RESULTS}

\section{Interpretation of the total specific deposit}

Kawamura (2000) provided guidelines for interpreting the specific deposit results, provided in the second column of Table 1. These guidelines apply to the soft deposits remaining after a plant backwash, or more formally to our framework, [ABW - APS]. In the third column, these guidelines were converted to the units used in this paper, using typical values found in our studies.

The final column in Table 1 shows our guideline developed for South African surface water treatment plants, which is about 2 to 3 times higher than the Kawamura guideline. This guideline was compiled by a visit to 8 different South African water treatment plants. The beds were closely inspected visually, in conjunction with their backwash patterns, by experienced observers, and the beds were classified in accordance with the categories in Table 1. By measuring the specific deposit in each bed, the classification could be quantified as indicated in Table 1.

\section{Further characterisation of the specific deposit}

Now having a test to quantify the specific deposit, a further test was developed to better characterise the specific deposit once stripped from the media. By determining the acid solubility (by adding a strong acid) and the volatility (by incineration at $550^{\circ} \mathrm{C}$ ) of the specific deposit, it could be fractionated into 4 parts:

- The non-soluble non-volatile (NSNV) fraction, corresponding to the inorganic particles in the raw water.

- The soluble non-volatile (SNV) fraction, corresponding to the chemical precipitates formed upon chemical dosing.

- The non-soluble volatile (NSV) fraction, corresponding to organic material such as algal biomass and organic detritus. 


\begin{tabular}{|l|l|l|l|}
\hline \multicolumn{5}{|c|}{ TABLE 2 } \\
\hline & Soluble & Non-soluble & Total \\
\hline Volatile & $\begin{array}{l}\text { SV } \\
(\mathrm{A}-\mathrm{B}-\mathrm{C}+\mathrm{D})\end{array}$ & $\begin{array}{l}\text { NSV } \\
(\mathrm{B}-\mathrm{D})\end{array}$ & $(\mathrm{A}-\mathrm{C})$ \\
\hline $\begin{array}{l}\text { Non- } \\
\text { volatile }\end{array}$ & $\begin{array}{l}\text { SNV } \\
(\mathrm{C}-\mathrm{D})\end{array}$ & $\begin{array}{l}\text { NSNV } \\
\text { D }\end{array}$ & $\begin{array}{l}\text { NV } \\
\text { C }\end{array}$ \\
\hline Total & $(\mathrm{A}-\mathrm{B})$ & $\begin{array}{l}\text { NS } \\
\text { B }\end{array}$ & $\begin{array}{l}\text { TSS } \\
\text { A }\end{array}$ \\
\hline
\end{tabular}

- The soluble volatile (SV) fraction has no clear origin. As this fraction was typically found to be small $(<10 \%)$, it is combined with the NSV fraction and simply considered to be an organic fraction.

Schematically, the breakdown is shown in Table 2. The experimental procedure outlined in Appendix 3 will provide direct measures of the shaded blocks in Table 2. The remaining fractions are obtained by subtraction.

\section{South African case studies}

Having developed a systematic framework and the required experimental procedures, 8 South African treatment plants were visited at 7 different locations in the period from May 2002 to January 2005, adding up to 31 plant visits. In general, the hard deposit [APS-ACS] fraction was surprisingly high. The median value was $35 \mathrm{~kg} / \mathrm{m}^{3}$, indicating a need for better $\mathrm{pH}$ control before filtration to reduce the predominantly calcium carbonate precipitation. During a typical plant backwash, the specific deposit washed out [BBW-ABW] had a median value of $1.9 \mathrm{~kg} / \mathrm{m}^{3}$, but it should be noted that not all of the filters were at the end of their filtration cycles when the samples were taken. The maximum value was $4.7 \mathrm{~kg} / \mathrm{m}^{3}$. One could thus assume that the plant backwash typically removed about $5 \mathrm{~kg} / \mathrm{m}^{3}$. The specific deposit remaining after backwash [ABW-APS] is our main concern, as indicated in the introduction. Figure 1, showing some typical results from 4 treatment plants, allows the following observations:

- The soft deposits [ABW-APS] remaining after plant backwash had a median value of $3.8 \mathrm{~kg} / \mathrm{m}^{3}$. This value indicates that about as much specific deposit remains on the media after plant backwashing as that which was washed out! This finding is disturbing, but in line with our earlier qualitative observations at many treatment plants. The median specific deposit is close to our guideline of $4 \mathrm{~kg} / \mathrm{m}^{3}$ for clean filters, but almost half the plants exceeded this guideline on some occasions. The proposed guidelines developed and shown in Table 1 are shown in bold lines.

- During summer visits when the water was warm (typically $20^{\circ} \mathrm{C}$ to $25^{\circ} \mathrm{C}$ ), the specific deposit was about twice as much as during winter months (water temperature $5^{\circ} \mathrm{C}$ to $10^{\circ} \mathrm{C}$ ).

- After plant backwashing, further laboratory washing removed a median of $1.3 \mathrm{~kg} / \mathrm{m}^{3}$, leaving $2.5 \mathrm{~kg} / \mathrm{m}^{3}$ that could not be washed at all, but required physical stripping in the laboratory. In most cases, the differences between summer and winter values were due to this [ACW - APS] fraction.

- The key to cleaner filter media is thus the [ACW - APS] fraction. This fraction cannot be removed by normal backwashing procedures, regardless of how effective they are. Some other chemical or physical auxiliaries are required.

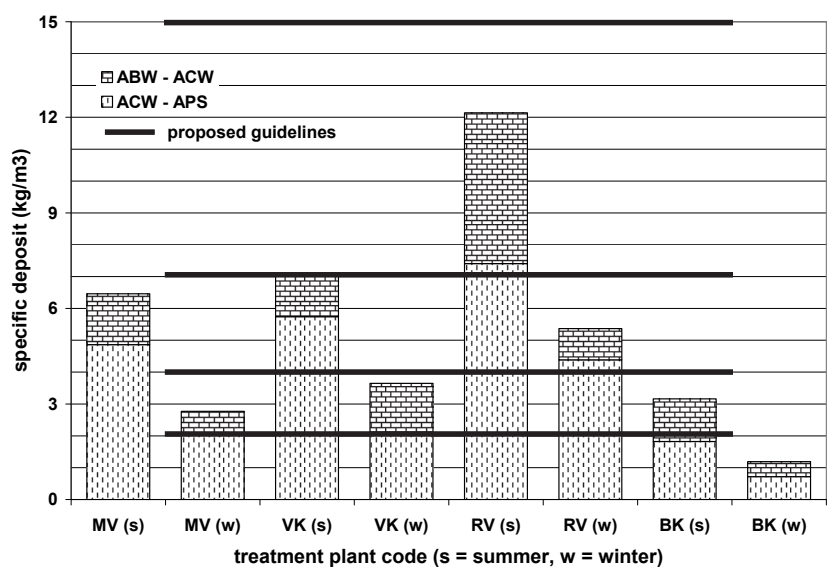

Figure 1

Specific deposit remaining after backwash at 4 treatment plants

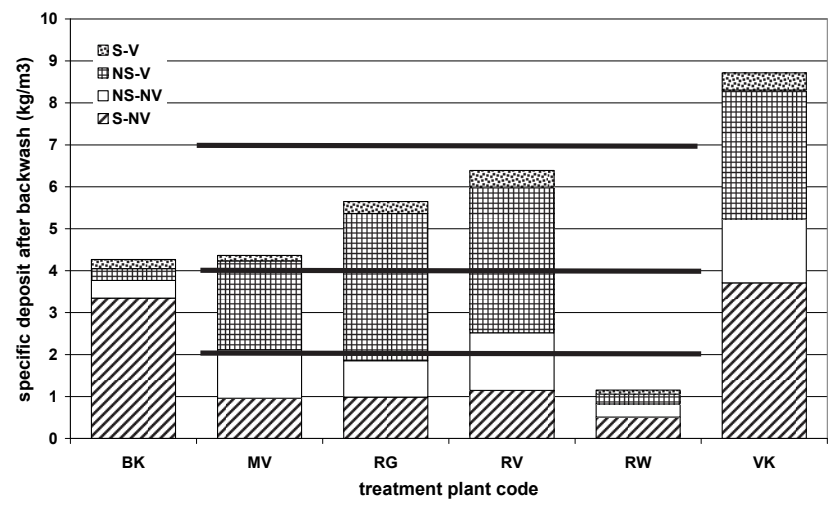

Figure 2

Average specific deposit fractions found at 6 treatment plants

The backwashing systems at the treatment plants were actually quite effective in terms of their own backwashing systems, removing approx. $5 /(5+1.3)=80 \%$ of the specific deposit from a dirty filter.

Figure 2 shows the average specific deposit [ABW - APS] at 6 treatment plants, broken down into the 4 fractions based on volatility and acid solubility. It suggests the following:

- The total specific deposits of 3 plants are at or below the guidelines where corrective action is suggested, leaving 3 plants where filter cleanliness is problematic.

- The SV (acid-soluble, volatile) fraction is consistently small in relation to the other fractions and can be grouped with the NS-V fraction to form the $\mathrm{V}$ fraction, indicative of organic material.

Figure 3 presents the data of Fig. 2 in a different form, showing the percentage contribution of each fraction, after consolidating the SV and NS-V fractions into a V fraction:

- There are large differences in the composition of the specific deposit.

- The high soluble, inorganic fraction at the BK treatment plant suggests that acid treatment may offer a means towards media rehabilitation. This treatment plant uses a lime-induced high-pH strategy, with some lime deposits carried over to the filters which are not completely washed during backwash.

- On the other hand, the specific deposit at the RG treatment 


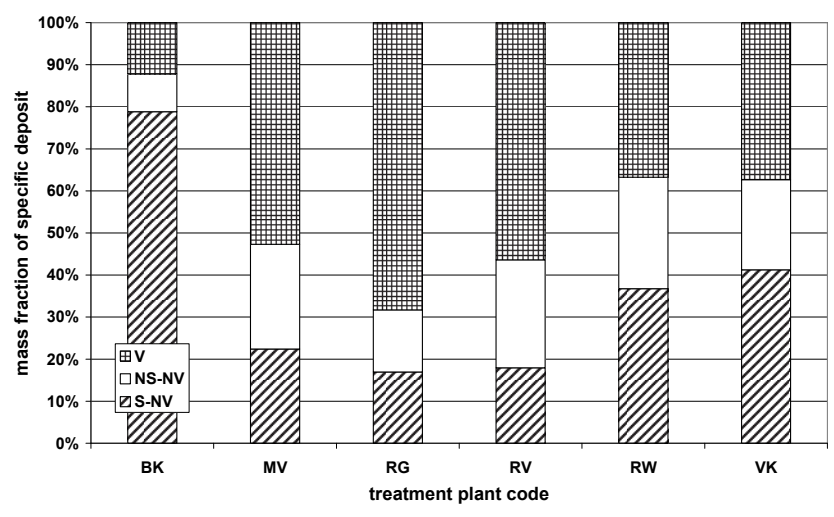

Figure 3

Percentage contribution of specific deposit fractions at 6 treatment plants

plant has a high organic fraction. The treatment plant treats eutrophic water and the samples were taken from GAC filters following DAF and sand filtration. These beds are prone to biofilm formation with significant effects on headloss and media expansion.

\section{SUMMARY AND CONCLUSIONS}

The problem of dirty filter media at water treatment plants, despite having good backwash systems, is a serious problem that requires constant monitoring and maintenance. This paper firstly proposes a standard procedure for quantification of the specific deposit on filter media. This method is based on the idea of physical stripping of the deposit from the media proposed by Kawamura (2000), but brings radical refinements in terms of the stripping procedure, measurement and reporting of the results. Guidelines for the interpretation of the results have been developed for South African conditions which are higher, but comparable with the guidelines proposed by Kawamura.

The paper secondly proposes a standard procedure for the characterisation of the specific deposit, based on its volatility and its acid solubility. These fractions loosely correspond to the chemical precipitates formed during treatment, the insoluble solids from the raw water, and an organic fraction.

The utility of the proposed procedures is thirdly demonstrated by a brief summary of an extended survey of South African treatment plants. It shows that there is a real problem with recalcitrant specific deposit that cannot be readily removed by backwashing, a fraction that correlates with the organic fraction in the specific deposit. The survey confirms that the proposed procedures are useful for the more detailed and rational diagnosis of the cause, and possibly the rehabilitation of dirty filter media.

\section{REFERENCES}

AWWA (AMERICAN WATER WORKS ASSOCIATION) (1990) Water Quality and Treatment: A Handbook of Community Water Supplies ( $4^{\text {th }}$ edn.). McGraw-Hill, Inc., New York.

APHA (American Public Health Association) (1992) Standard Methods for the Examination of Water and Wastewater ( $18^{\text {th }}$ edn.). American Public Health Association, Washington, DC.

BAYLIS JR (1935a) A study of filtering materials for rapid sand filters Part 4: Washing rapid sand filters. Water Works and Sewerage January 1935.

BAYLIS JR (1935b) A study of filtering materials for rapid sand filters Part 6: Mud ball formation and measurement - miscellaneous items. Water Works and Sewerage September 1935.

CLEMENTS M (2005) Biofilm on filtration media. D.Eng. thesis, University of Johannesburg.

HAARHOFF J and VAN STADEN SJ (2006) Measuring the cleanliness of filter media. Ninth WISA Biennial Conference, 22-24 May 2006, Durban.

HAARHOFF J, VAN STADEN SJ, GELDENHUYS J, SIBIYA M, NAICKER P and ADAM N (2008) Assessments and improvement of filter media cleanliness in rapid gravity sand filters. WRC Report No. 1525/1/08. Water Research Commission, Pretoria.

HUDSON HE (1981) Water Clarification Processes - Practical Design and Evaluation. Van Nostrand Reinhold Company, New York.

KAWAMURA S (2000) Integrated Design and Operation of Water Treatment Facilities ( $2^{\text {nd }}$ edn.). John Wiley \& Sons, Inc., Oxford.

LOGSDON GS, HESS AF, CHIPPS MJ and RACHWAL AJ (2002) Filter Maintenance and Operations Guidance Manual. AWWA Research Foundation, Denver, USA.

LOMBARD HK and HAARHOFF J (1995) Filter nozzle and underdrain systems used in rapid gravity filtration. Water SA 21 (4) 281-298.

VAN STADEN SJ and HAARHOFF J (2004a) A standard test for filter media cleanliness. Water $S A 30$ (1) 81-88.

VAN STADEN SJ and HAARHOFF J (2004b) What simple media tests can tell you about filter problems and rehabilitation. Proc. Eighth WISA Biennial Conference, 2-6 May, 2004, Cape Town.

VAN STADEN SJ and HAARHOFF J (2004c) An improved filter media test for troubleshooting and rehabilitation of problem filters. Paper 00009892. Proc. Water Quality and Technology Conference, 14-18 November, 2004, San Antonio, Texas.

VAN STADEN SJ and HAARHOFF J (2006) Effective filter backwashing with multiple washes of air and water. Ninth WISA Biennial Conference. 22-24 May 2006, Durban.

\section{APPENDIX 1 \\ Suggested procedure for determination of soft specific deposit on filter media}

A full-scale filter is cored with a $35 \mathrm{~mm}$ diameter thin-walled tube throughout the bed depth in at least 3 locations, after scraping off the top $10 \mathrm{~mm}$ of the media to prevent inclusion of surface debris. The media obtained is gently homogenised with a riffle splitter. About $250 \mathrm{~m} \ell$ of media is sealed in a plastic bag and refrigerated for analysis soon thereafter in the laboratory. Approximately 40 to $60 \mathrm{ml}$ of media is weighed, dried at $105^{\circ} \mathrm{C}$ and reweighed to determine the moisture content (MC) of the media. A further 3 samples of approximately $60 \mathrm{ml}$ each are measured out and weighed. Using MC, the dry media mass (DMM) of each sample is determined. Each sample is then treated as follows:
The sample is placed in a $250 \mathrm{~m} \ell$ measuring cylinder, with $100 \mathrm{~m} \ell$ tap water, sealed and inverted 20 times, with short pauses between inversions to allow the media to settle. The resultant suspension is drained into a $500 \mathrm{~m} \ell$ Erlenmeyer flask. The water addition, inversion and draining procedure is repeated 4 times, adding the suspension to the same flask. Once $500 \mathrm{~m} \ell$ of dirty suspension is collected, its total suspended solids (TSS) is measured. The specific deposit is calculated as:

$$
\text { specific deposit }\left[\mathrm{kg} / \mathrm{m}^{3}\right]=\frac{\operatorname{TSS}[\mathrm{mg} / \mathrm{l}] \cdot \rho\left[\mathrm{kg} / \mathrm{m}^{3}\right] \cdot(1-\varepsilon)}{2000 \cdot D M M[\mathrm{~g}]}
$$


with:

$\rho$ the media grain density

$\varepsilon$ the filter bed porosity
The median value of these triplicate results is suggested as a fair representation of the specific deposit on the filter media.

\section{APPENDIX 2
Suggested procedure for determination of washable specific deposit from backwash water}

Representative samples of the dirty backwash water have to be taken at least every 30 s over the duration of the backwash period. Samples spaced evenly in time simplify the calculations, but more frequent samples may be taken during the first 2 min of backwash when the bulk of the solids are washed out. If possible, samples must be taken from a collection channel rather than at the first overflow weir to overcome the 'streakiness' due to the uneven cleaning of adjacent media patches. The timing of samples has to compensate for the travel time from the centre of the media bed to the sampling point. Samples of $200 \mathrm{ml}$ are transferred to bottles and their TSS determined in the laboratory (Standard Method 209C) (APHA, 1992).
The backwash rate should be measured in situ by closing the backwash discharge valve while the backwash pumps are running. By noting the time taken for the water to rise at least $500 \mathrm{~mm}$ within the filter box (the distance between adjacent rungs of a ladder firmly positioned in the filter is convenient), the backwash rate (BR) is calculated directly (after correcting for the area occupied by the backwash trough or other filter box intrusions). Measure the bed depth (BD) by probing with a thin rod at a few positions. The specific deposit is calculated as:

specific deposit $\left[\mathrm{kg} / \mathrm{m}^{3}\right]=\frac{B R[\mathrm{~mm} / \mathrm{s}] \cdot \sum(T S S[\mathrm{mg} / \mathrm{l}] \cdot \mathrm{t}[\mathrm{s}])}{1000 \cdot B D[\mathrm{~mm}]}$ with:

$\mathrm{t}$ the backwash time represented by each sample.

\section{APPENDIX 3 \\ Suggested procedure for characterisation of specific deposit}

\section{Acid soluble and non-soluble fractions}

$10 \mathrm{~m} \ell$ of a $0.185 \mathrm{M}(6.4 \%) \mathrm{HCl}$ solution must be mixed with $100 \mathrm{ml}$ of the suspension and the total non-soluble solids (NS) determined using Standard Method 209C (APHA, 1992):

$$
N S(m g / \ell)=\frac{\text { non-soluble residue }(m g) \times 1000}{\text { sample }(m \ell)}
$$

\section{Volatile and non-volatile fractions}

Using Standard Method 209D (APHA, 1992) and the filtrates obtained for TSS and NS, the total non-volatile solids (NV) and the total non-soluble non-volatile solids (NSNV) of the sample can be determined:

$$
\begin{aligned}
& N V(m g / \ell)=\frac{\text { non-volatile residue }(m g) \times 1000}{\text { sample }(m \ell)} \\
& \operatorname{NSNV}(m g / \ell)=\frac{\text { non-soluble non-volatile residue }(m g) \times 1000}{\operatorname{sample}(m \ell)}
\end{aligned}
$$

These fractions can be expressed in terms of $\mathrm{kg} / \mathrm{m}^{3}$ by substituting each fraction in the place of TSS in the equation in Appendix 1. 